\title{
MEMBANGUN APLIKASI PEMBELIAN DAN PENJUALAN PADA TOKO ARJUNA CAM STORE
}

\author{
Arif Maulana ${ }^{1}$, Rudi Prasetya ${ }^{2}$, Sutrisno ${ }^{3}$ \\ ${ }^{1,2,3}$ Teknik Informatika, Fakultas Teknik dan Ilmu Komputer, Universitas Indraprasta PGRI Jakarta \\ Jalan Raya Tengah No 80, Kelurahan Gedong, Pasar Rebo, Jakarta Timur \\ 1zhein0008@gmail.com, 2 rudiprasetya1@gmail.com, ${ }^{3}$ sutrisno3831@gmail.com
}

\begin{abstract}
ABSTRAK
Permasalahan yang terdapat pada Toko Arjuna Cam Store adalah proses pembelian dan transaksi penjualan masih manual dengan menggunakan buku besar dalam setiap pencatatan nya, sehingga sering terjadi kesalahan-kesalahan yang akan menyebabkan kerugian bagi Toko Arjuna Cam Store dan pembuatan laporan kepada pemilik toko masih membutuhkan banyak waktu sehingga tidak efisien. Tujuan merancang suatu sistem informasi pembelian dan penjualan ini dengan tujuan untuk memudahkan admin dalam memproses pengolahan data yang ada saat ini. Perangkat aplikasi yang telah dibuat dengan bahasa pemrograman Java NetBeans 8.0.2 dan penyimpanan data pada database MySQL dapat memberikan kelancaran dalam proses menginput dan penyimpanan data-data serta laporan-laporan yang diberikan kepada pemilik toko. Dengan menggunakan metode pengembangan sistem yaitu Waterfall dalam penelitian ini adalah dengan tahapan-tahapan seperti rekayasa sistem, analisis, desain, coding, testing, dan maintenance. Hasil dari penelitian ini menciptakan suatu sistem informasi pembelian dan penjualan dapat memudahkan pihak toko dalam proses pendataan data barang, data pembelian barang, data penjualan serta data return pembelian yang lebih baik dan akurat.
\end{abstract}

Kata Kunci: Aplikasi, Pembelian, Penjualan, Desktop

\begin{abstract}
The problem found in the Arjuna Cam Store Store is that the process of buying and selling sales transactions is still manual by using a ledger in each of its records, so mistakes often occur that will cause losses for the Arjuna Cam Store Store and making reports to store owners still takes a lot of time. so inefficient. The purpose of designing a buying and selling information system is to make it easier for admins to process the current data processing. Applications that have been made with the Java NetBeans 8.0.2 programming language and data storage in the $M y S Q L$ database can provide smooth processing of input and storage of data and reports provided to shop owners. By using the system development method, namely Waterfall, in this research, the stages are systems engineering, analysis, design, coding, testing, and maintenance. The results of this study create a purchasing and sales information system that can facilitate the store in the process of collecting data on goods, purchase data, sales data and purchase return data that is better and more accurate.
\end{abstract}

Key Word: Application, Purchase, Selling, Desktop

\section{PENDAHULUAN}

Kemajuan teknologi informasi dan komputer di Indonesia merupakan salah satu yang paling pesat dibandingkan bidang yang lainnya. Perkembangan teknologi ini dirasakan dalam kurun waktu belakangan ini dalam segi aspek perdagangan dengan skala kecil, besar hingga nasional sehingga teknologi informasi ini sangat dirasakan manfaatnya oleh pelaku usaha khusus nya usaha penjualan elektronik seperti Toko Cam Store(Narandia, Ningsih, \& Aprilliah, 2014).
Toko Arjuna Cam Store merupakan toko yang profesional yang bergerak dibidang elektronik dengan didukung oleh tenaga ahli berpendidikan yang kredibel. Tetapi ada permasalahan didalam pendataan proses pembelian dan penjualan karena semua nya dikerjakan secara manual tidak adanya suatu sistem informasi sebagai penunjang proses tersebut (Sholikhah, Sairan, \& Syamsiah, 2017).

Permasalahan yang paling signifikan adalah pada proses penginputan data, proses pembelian barang ke supplier dan transaksi penjualan serta laporan 
ini masih dilakukan secara manual, sehingga data yang didapat seringkali bermasalah karena kesalahan dari manusia, misalnya ketika bagian administrasi membutuhkan informasi mengenai stok barang masuk dan barang keluar maka harus dilakukan pengecekan ke gudang dan melakukan pengontrolan barang. Pelaporan data penjualan sering sekali terlambat pada saat penyerahan laporan bulanan kepada pemilik toko (Sari, 2017).

Perancangan sistem informasi yang akan diterapkan dapat memudahkan dalam pengolahan data sehingga mendapatkan manfaat yaitu membantu dalam proses mengolah data secara baik dan cepat sehingga dapat memudahkan penginputan dan pencarian data sehingga dapat mengurangi kesalahan data kemudian mempermudah admin untuk proses pembuatan laporan setiap bulannya dari laporan keuangan, laporan penjualan, dan laporan pembelian barang kepada supplier (Hariyanto, 2014).

Dengan permasalahan tersebut, perlu ada nya suatu sistem yang terkomputerisasi dalam penyelesaiannya. Sistem adalah sekumpulan komponen yang saling terintegrasi satu sama lain yang dapat berinteraksi bersama-sama mencapai tujuan yang diinginkan oleh pengguna nya (Sutabri, 2012). Sistem merupakan suatu kumpulan dari komponen-komponen yang membentuk satu kesatuan (Tyoso, 2016). Pembangunan sistem adalah sekumpulan aktivitas yang menggambarkan secara rinci bagaimana sistem akan berjalan. Hal itu bertujuan untuk menghasilkan produk perangkat lunak yang sesuai dengan kebutuhan user (Satzinger, J. W., Jackson, R. B., Burd, n.d.).

Diharapkan dengan adanya suatu sistem informasi dapat menangani permasalahan yang ada di perusahaan tersebut. Selain itu, proses transaksi penjualan menjadi lebih baik dan cepat dalam proses penginputan data, pencarian data serta dalama proses pelaporan data untuk pimpinan perusahaan (Prasojo, 2011)

Aplikasi ini dapat memudahkan pekerjaan Admin dalam melaksanakan pembuatan laporan dan dapat memudahkan toko dalam memproses data pembelian dan penjualan pada Toko Arjuna Cam Store.

\section{METODE PENELITIAN}

Peneliti menggunakan metode Research and Development dalam penyelesaian penelitian ini. (Sugiyono, 2016). Dalam pelaksanaan R\&D, ada beberapa metode yang digunakan yaitu metode deskriptif, evaluatif dan eksperimental. Metode penelitian deskriptif digunakan dalam penelitian awal untuk menghimpun data tentang kondisi yang ada yaitu penulis membutuhkan data-data yang dapat menunjang tercipta nya suatu sistem informasi penjualan seperti data barang, data pelanggan, data pembelian data penjualan dan data return pembelian terdahulu yang masih tersimpan secara manual didalam buku besar. Metode evaluatif digunakan untuk mengevaluasi proses ujicoba pengembangan suatu produk, dalam proses ini penulis melakukan ujicoba terhadap suatu sistem yang telah dirancang agar tidak ada terjadi kesalahan dalam proses penginputan data serta pelaporan bulanan kepada pemilik toko. Dan metode eksperimen digunakan untuk menguji keampuhan dari produk yang dihasilkan, dalam proses yang terakhir ini perlu dilakukan pengujian akhir yang diharapkan bahwa sistem yang dirancang oleh penulis dapat berjalan dengan baik dan sesuai dengan kebutuhan dan terfokus pada proses pembelian dan penjualan pada Toko Arjuna Cam Store (Putra, 2011).

\section{HASIL DAN PEMBAHASAN Analisa Permasalahan}

Dari pembahasan diatas penulis mengambil simpulan atas permasalahan yang ada diantaranya:

1. Penulisan data masih dilakukan secara manual dalam pencatatan data pembelian dan penjualan maupun dalam pembuatan laporan.

2. Proses pencatatan secara manual memerlukan tempat penyimpanan yang sangat luas, akibat kertas yang bertumpuk serta memerlukan waktu yang lama dalam proses pencarian kembali data.

3. Pelayanan terhadap pelanggan menjadi tidak efisien dan mungkin akan terjadi kesalahan akibat waktu yang lama dalam pencarian data.

\section{Alternatif Penyelesaian Masalah}

Berdasarkan analisis sistem yang sedang berjalan saat ini penulis melihat kelemahan-kelemahan dan pokok permasalahan yang terdapat pada sistem pembelian dan penjualan pada Toko Arjuna Cam 
Store, maka penulis dapat menyarankan beberapa alternatif permasalahan yang dapat dicoba, yaitu:

1. Agar tidak terjadi keterlambatan didalam proses pengerjaan informasi, sebaiknya dikoordinasi dengan baik dan terkomputerisasi dengan benar antara sub sistem yang satu dengan yang lainnya, dan sebaiknya Toko Arjuna Cam Store membuat rancangan sistem yang dapat meringankan dalam bertransaksi, membuat laporan, mengecek data-data khususnya pada penjualan.

2. File atapun data yang sudah dikerjakan sebaiknya disimpan ke Harddisk ataupun alat penyimpanan data yang lain, dan jika perlu dibuat backupnya jika saat teradi kesalahan memiliki cadangan file ataupun data-data.

3. Alangkah baiknya bila komputer yang digunakan untuk memproses data di upgrade, sehingga pemrosesan data tersebut dapat dilakukan lebih baik, cepat dan tepat.

Dirancangnya suatu sistem informasi pembelian dan penjualan pada Toko Arjuna Cam Store yang terkomputerisasi ini, diharapkan dapat mempermudahkan proses pengerjaan dan pengecekan data khususnya pada proses pembuatan laporan dan transaksi penjualan.

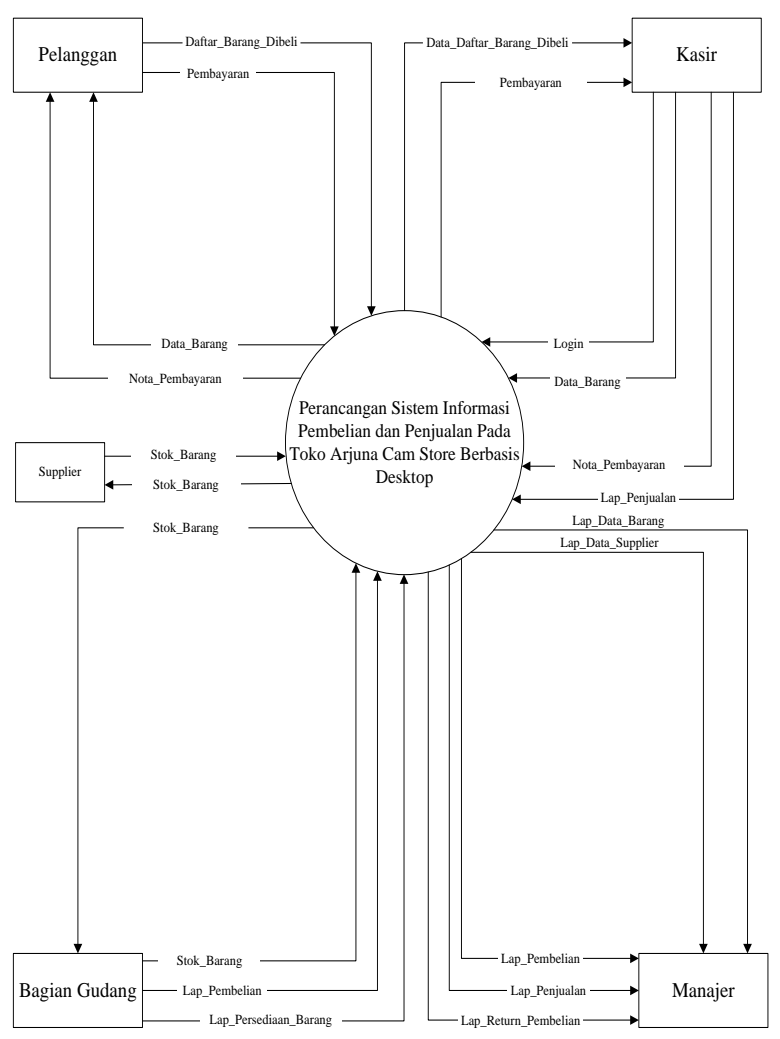

Gambar 1. Diagram Konteks

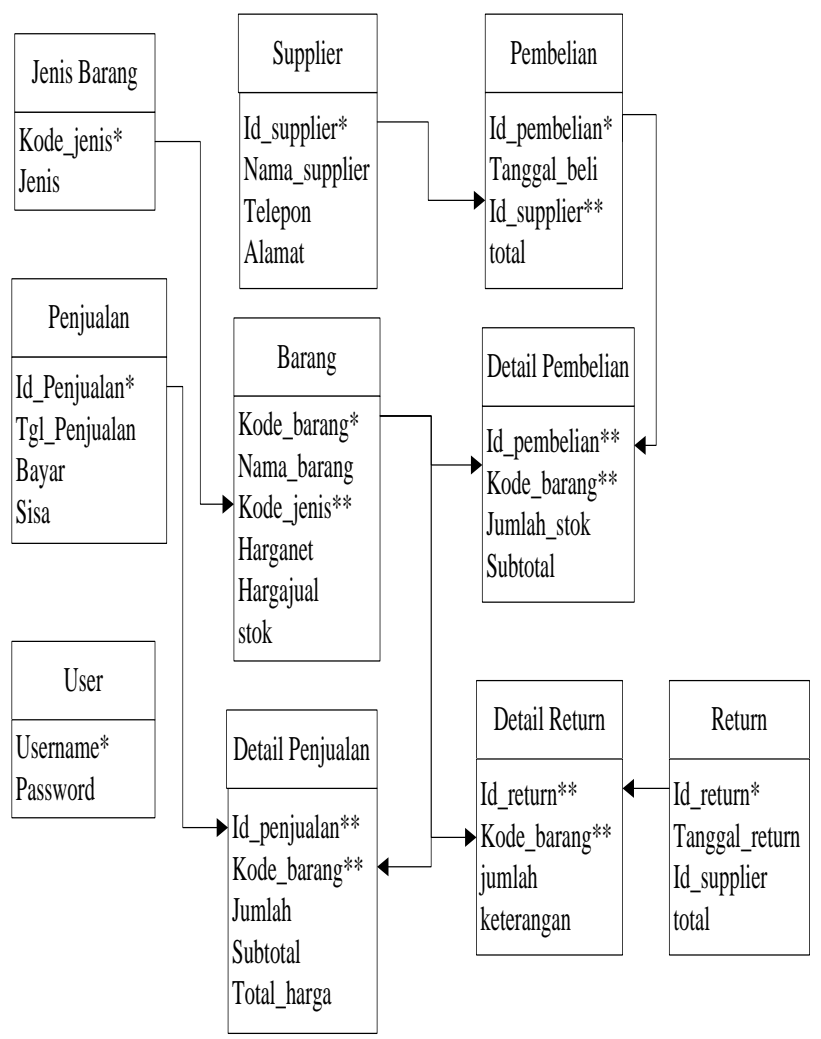

Gambar 2. Normalisasi 


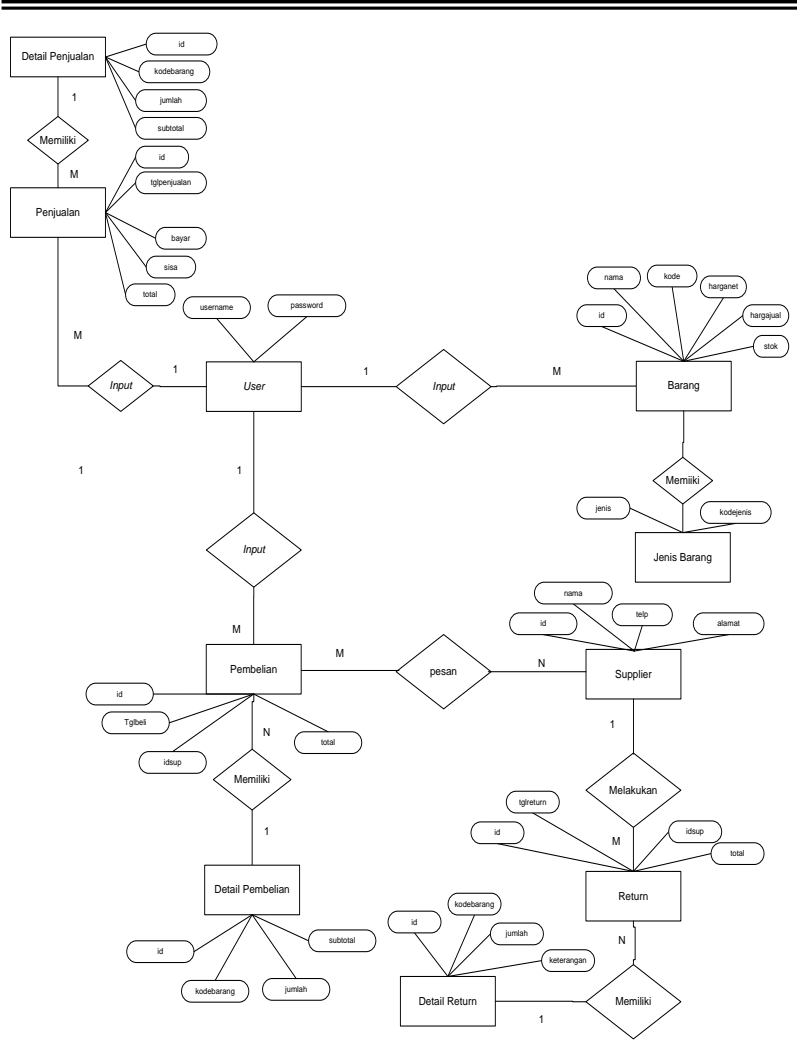

Gambar 3. ERD (Entity Relationship Diagram)

Berikut adalah tampilan layar dan hasil pengujian pada software program yang telah di buat dengan bahasa pemrograman Java.

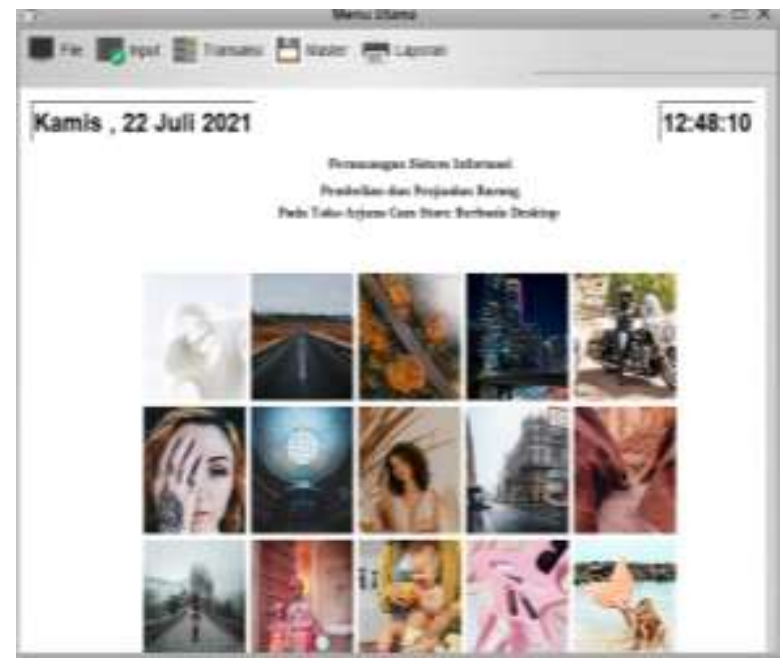

Gambar 4. Form Menu Utama

Layar di atas menampilkan tampilan Menu Utama pada Aplikasi Pembelian dan Penjualan Pada Toko Arjuna Cam Store. Pada layar utama tersedia menu bar yang terdiri dari master data yang digunakan untuk memasukkan data yang berkaitan dengan data jenis barang, data barang, data supplier, data pembelian, data penjualan, data return pembelian, dan laporan-laporan.

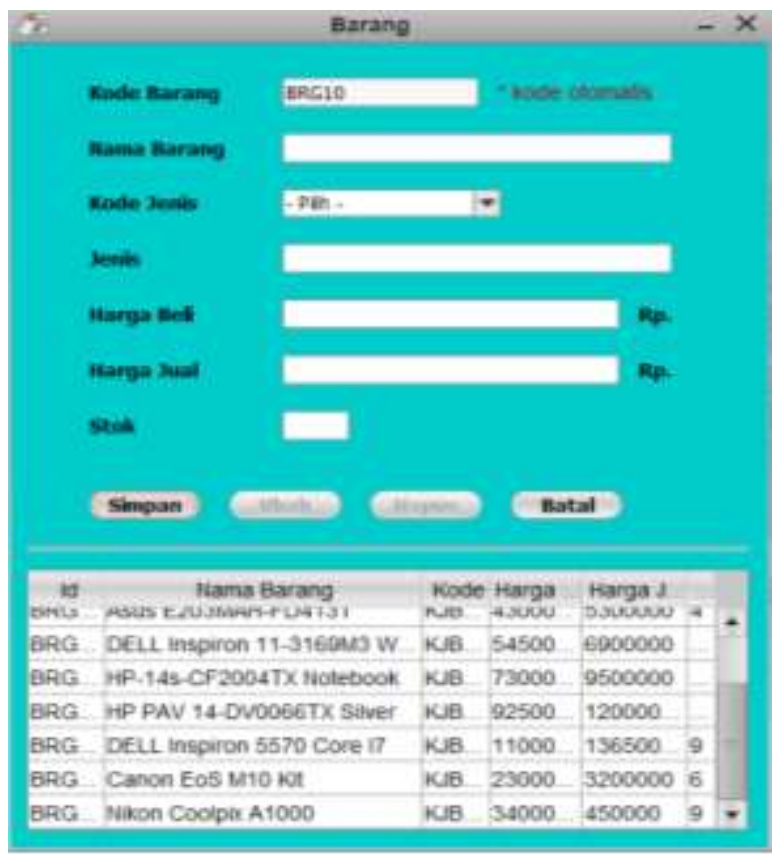

Gambar 5. Form Data Barang

Layar di atas menampilkan tampilan form data barang. Pada layar form data barang untuk menginput data barang yang terdiri dari Kode Barang, Nama Barang, Kode Jenis, Jenis Barang, Harga Beli, Harga Jual dan Stok.

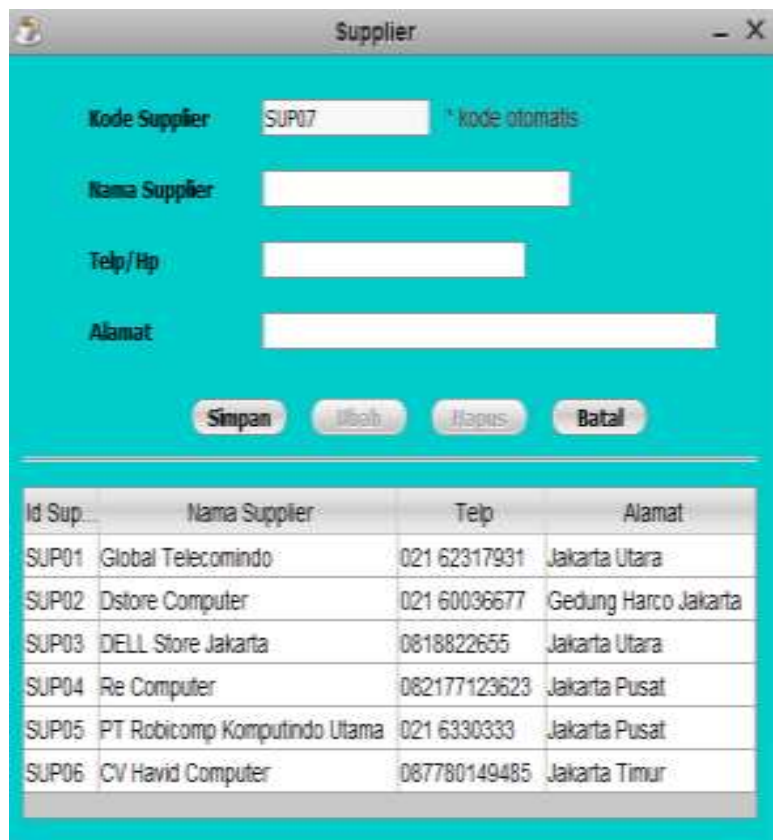

Gambar 6. Form Data Supplier 
Layar di atas menampilkan tampilan form data supplier. Pada layar form data supplier untuk meng-input data supplier yang terdiri dari Kode Supplier, Nama Supplier, No Telp dan Alamat.

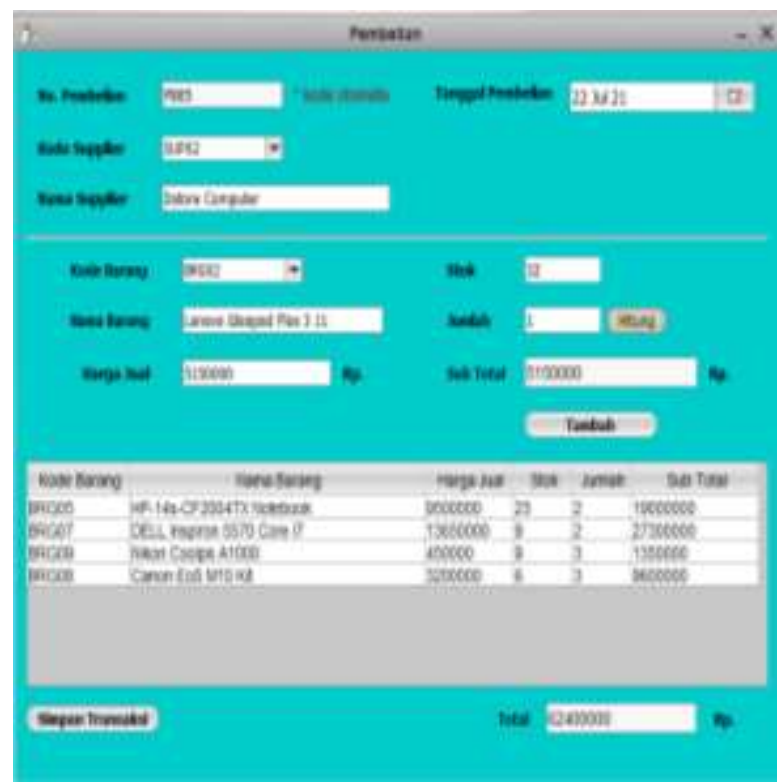

Gambar 7. Data Form Data Transaksi Pembelian

Layar di atas menampilkan tampilan form data transaksi pembelian. Pada layar form data transaksi pembelian untuk meng-input data transaksi pembelian yang terdiri dari No Pembelian, Tgl Pembelian, Kode Supplier, Nama Supplier, Kode Barang, Nama Barang, Harga Jual, Stok, Jumlah dan Sub Total.

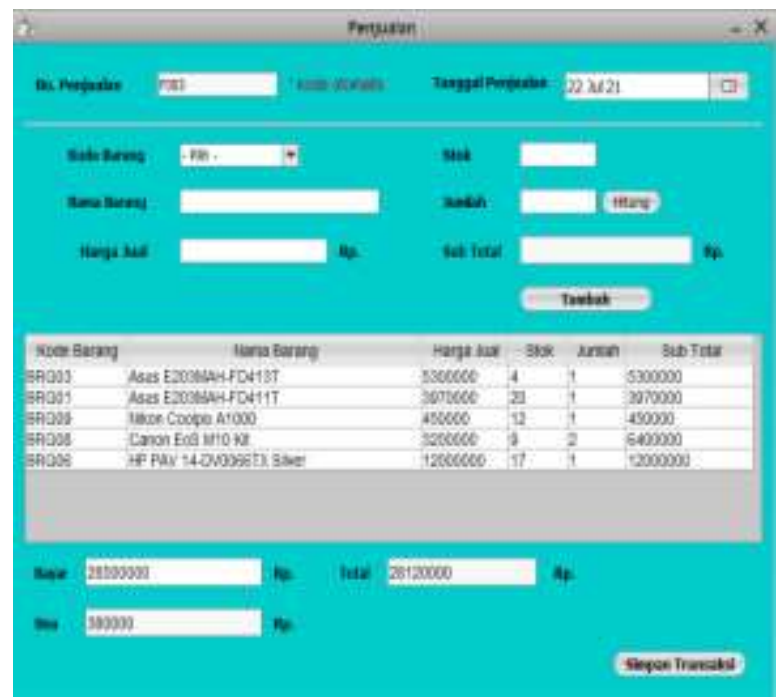

Gambar 8. Form Data Transaksi Penjualan

Layar di atas menampilkan tampilan form data transaksi penjualan. Pada layar form data transaksi penjualan untuk meng-input data transaksi penjualan yang terdiri dari No Penjualan, Tgl Penjualan, Kode Barang, Nama Barang, Harga Jual, Stok, Jumlah dan Sub Total.

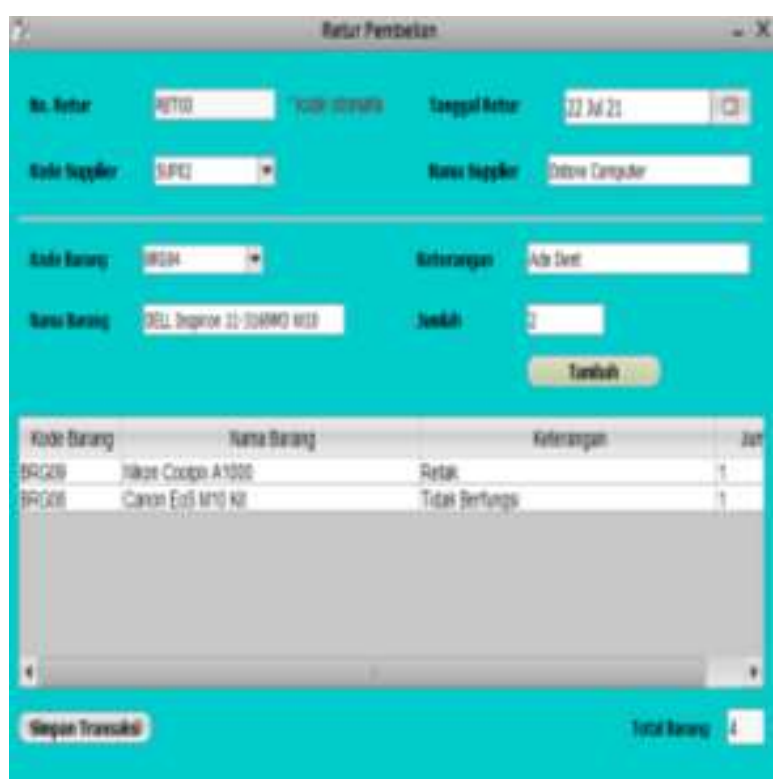

Gambar 9. Laporan Data Return Pembelian

Layar di atas menampilkan tampilan form data return pembelian. Pada layar form data return pembelian untuk meng-input data return pembelian yang terdiri dari No Retur, Kode Supplier, Nama Supplier, Tanggal Retur, Kode Barang, Nama Barang, Keterangan dan Jumlah.

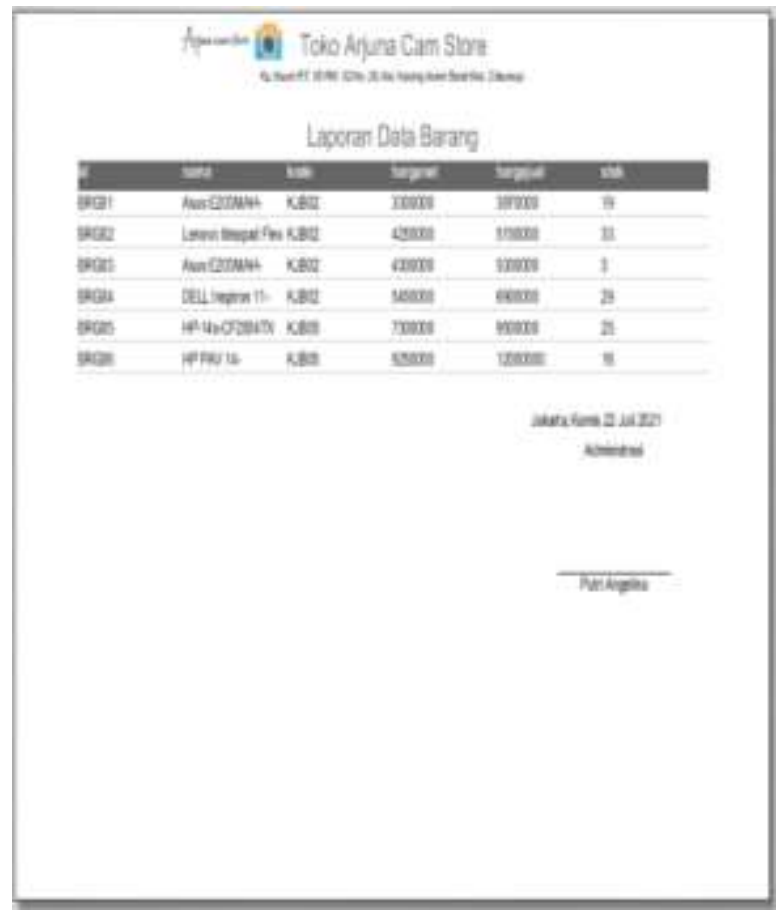

Gambar 10. Laporan Data Barang 
Layar di atas menampilkan tampilan form laporan data barang. Pada layar form data barang digunakan untuk mengecek laporan data barang terdiri Kode Barang, Nama Barang, Kode Jenis, Jenis Barang, Harga Beli, Harga Jual dan Stok.

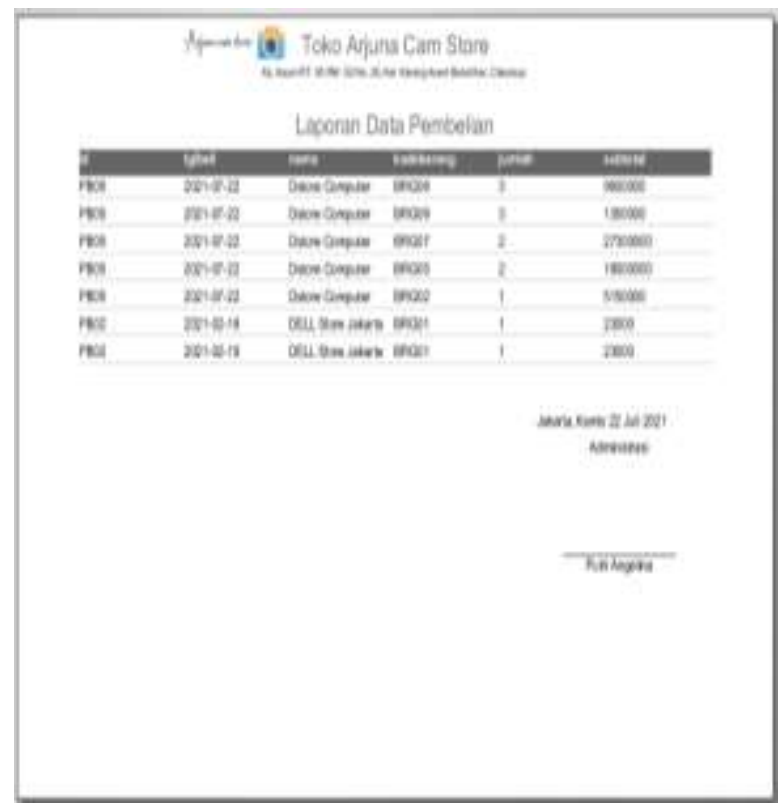

Gambar 11. Laporan Data Pembelian

Layar di atas menampilkan tampilan bukti pengembalian mobil. Pada layar bukti pengembalian mobil terdiri dari Kode Pengembalian, Tgl Kembali, ID Petugas, Nama Petugas, ID Booking, NIK, Nama Karyawan, Model dan Keterangan.

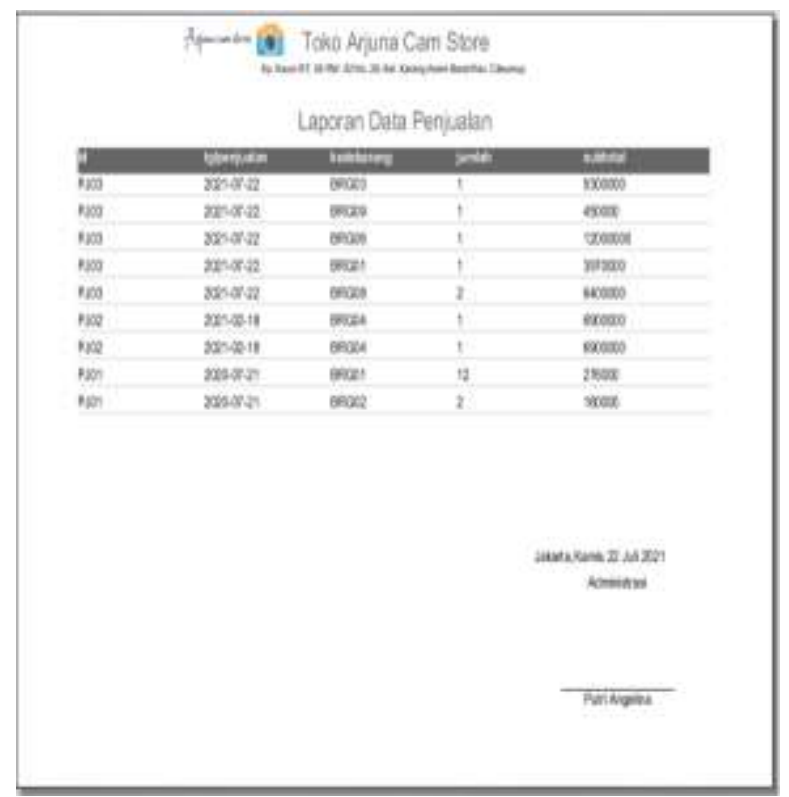

Gambar 12. Laporan Data Penjualan
Layar di atas menampilkan tampilan form laporan data penjualan. Pada layar form data penjualan digunakan untuk mengecek laporan data penjualan terdiri No Penjualan, Tgl Penjualan, Kode Barang, Jumlah dan Sub Total.

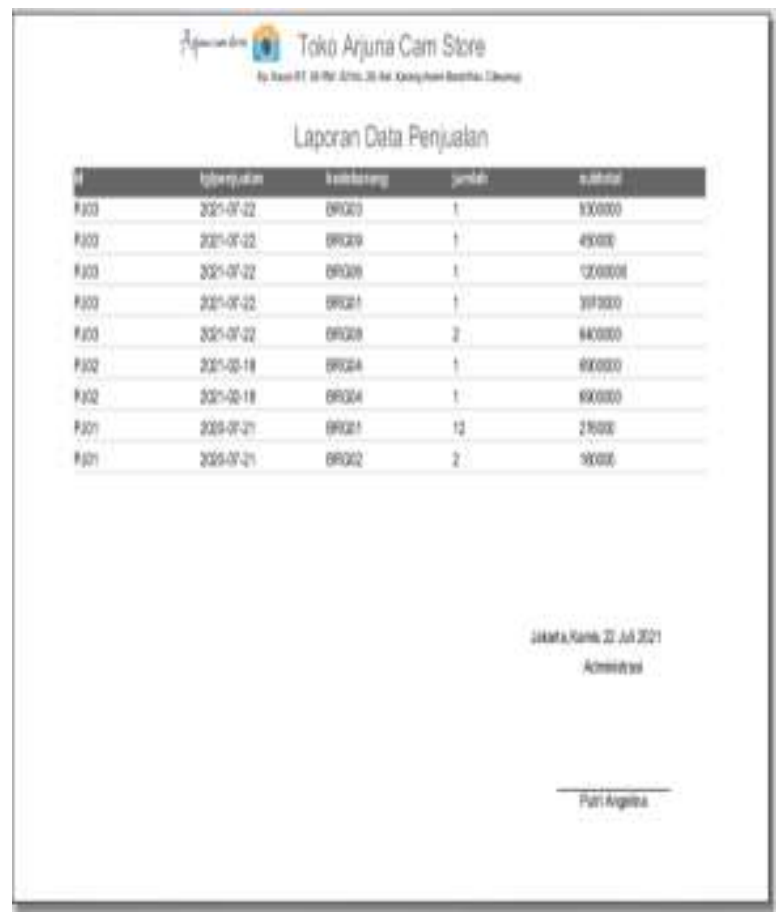

Gambar 13. Laporan Data Return Pembelian

Layar di atas menampilkan tampilan form laporan data retur pembelian. Pada layar form data retur pembelian digunakan untuk mengecek laporan data retur pembelian terdiri No Retur, Tanggal Retur, Nama Supplier, Kode Barang, Jumlah, Keterangan.

\section{SIMPULAN DAN SARAN}

Sistem aplikasi yang dirancang sudah layak digunakan untuk proses pembelian dan penjualan pada Toko Arjuna Cam Store karena sudah sesuai dengan kebutuhan, sehingga dapat mempermudah administrasi dalam proses penginputan data serta pembuatan laporan dengan memiliki form inputan data jenis barang, data barang, data supplier, data transaksi pembelian, data transaksi penjualan, data return pembelian serta memiliki 5 laporan yaitu laporan data barang, laporan data supplier, laporan pembelian, laporan penjualan, laporan return pembelian. 
Sarannya adalah perlu dikembangkan lebih baik lagi tidak hanya pada proses transaksi penjualan secara tunai akan tetapi bisa juga secara kredit.

\section{DAFTAR PUSTAKA}

Hariyanto. (2014). Permasalahan Bahasa Pemograman Java. Bandung: Informatika Bandung.

Narandia, L., Ningsih, R., \& Aprilliah, W. (2014). Perancangan Program Akuntansi Pembelian Dan Penjualan Barang Dagang Pada Pt. Dci Cikarang. Jurnal Sistem Informasi STMIK Antar Bangsa, III(2), 290-297.

Prasojo, M. (2011). Pengantar Sistem Informasi Manajemen bandung: CV. Remadja Karya.

Putra, N. (2011). Research and Development, Penelitian dan Pengembangan: Suatu Pengantar. Jakarta: PT Raja Grafindo Persada.

Sari, Y. P. (2017). Rancang Bangun Aplikasi Penjualan Dan Persediaan Di Kota Prabumulih. Jurnal Sistem Informasi Dan Komputerisasi Akuntansi (JSK).

Satzinger, J. W., Jackson, R. B., Burd, S. D. (n.d.). System Analysis and Design in A Changing World. USA: Cengage Learning.

Sholikhah, I., Sairan, M., \& Syamsiah, N. O. (2017). Aplikasi Pembelian Dan Penjualan Barang Dagang Pada CV Gemilang Muliatama Cikarang. Teknik Komputer AMIK BSI, III(1), 16-23.

Sugiyono. (2016). Metode Penelitian Kuantitatif, Kualitatif dan $R \& D$. Bandung: PT Alfabet.

Sutabri, T. (2012). Analisis Sistem Informasi. Yogyakarta: Andi.

Tyoso, J. S. P. (2016). Sistem Informasi Manajemen. Yogyakarta: DeePublish. 